\title{
COMMUNICATION
}

\section{PUMPed about Math: CSU Northridge Wins Exemplary Program Award}

\author{
Allyn Jackson
}

For many kids growing up in the San Fernando Valley of Los Angeles County, the default university is California State University Northridge (CSUN). It's not a "destination campus"; it's the campus down the street. CSUN (pronounced "see-sun") has more than 40,000 students, around half of them low-income and around 40 percent Hispanic. Most commute to campus, and many work parttime or even full-time and juggle complex family lives. Many are the first in their families to attend college, so their aspirations don't stretch beyond a bachelor's degree. Those who choose mathematics as a major typically see exactly one career option: teaching high school math.

So how did it come about that, in the past decade, more than fifty CSUN math majors enrolled in $\mathrm{PhD}$ programs? And how is it that many of them landed in top-quality mathematics programs like Georgia, Utah, UCLA, Johns Hopkins, University of Illinois Urbana-Champaign, and University of Texas Austin? And how is it that some of them took postdocs at the likes of Dartmouth, Rice, and the Institut des Hautes Études Scientifiques in Paris? Perhaps the CSUN mathematics department is becoming a "destination department".

These surprising and inspiring developments stem from PUMP (Preparing Undergraduates through Mentoring towards PhDs), a program that originated in the CSUN mathematics department. Now encompassing an alliance of ten Cal State institutions, PUMP is making a significant contribution to increasing the number of mathematicians

Allyn Jackson is senior writer and deputy editor of Notices. Her email address is axj@ams.org.

For permission to reprint this article, please contact:

reprint-permission@ams.org.

DOI: http://dx.doi.org/10.1090/noti1384 who are members of groups traditionally underrepresented in the field. It is also profoundly changing the lives of the students it touches. For initiating PUMP and overseeing the program after its expansion to other campuses, the CSUN mathematics department has received the AMS Award for an Exemplary Program or Achievement in a Mathematics Department.

\section{Upping Commitment to Underrepresented Students}

The CSUN mathematics department, which grants bachelor's and master's degrees, has always had a commitment to encouraging students underrepresented in mathematics. After all, these are the students the department sees every day. With PUMP, this commitment has reached an entirely new level over the past decade.

PUMP started on the initiative of CSUN mathematics professor Helena Noronha, a native of Brazil who earned her $\mathrm{PhD}$ at the Universidade Estadual de Campinas in 1983 and joined the CSUN faculty in 1990. Having served as a program officer in the Division of Mathematical Sciences of the National Science Foundation (NSF) from 2000 until 2002 (and later from 2009 to 2011), Noronha saw the potential for her department to have a national impact. She and three CSUN colleagues, Alberto Candel, Rabia Djellouli, and Werner Horn, developed the idea of PUMP and collaborated on a successful proposal to the NSF. Noronha was the principal investigator and the other three were co-principal investigators. With Noronha as director, PUMP started in 2005. Its main goal: prepare underrepresented minority students from the San Fernando Valley for success in $\mathrm{PhD}$ programs in the mathematical sciences.

"In the beginning we made probably every mistake we could have made, like any program startup," said Horn, who served as director of PUMP from 2009 to 2012. 


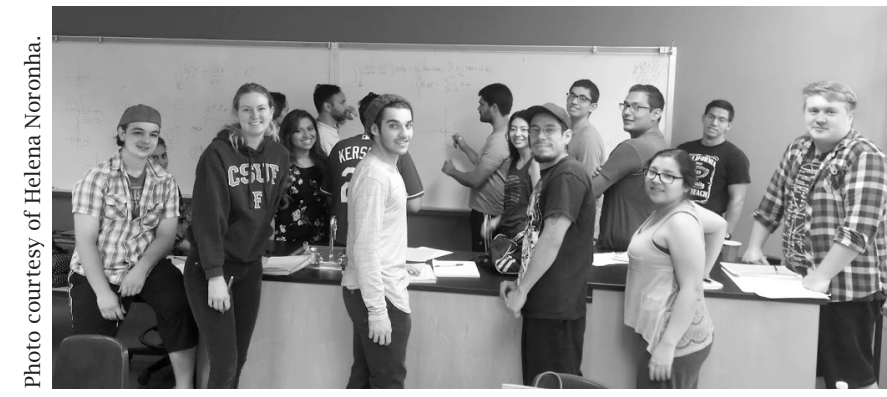

PUMP students discuss mathematics together.

Undiscouraged, the PUMP personnel used the knowledge gained to improve and fine-tune the program. For example, at the beginning PUMP emphasized to students the offer of stipends to help them prepare for graduate work in mathematics. The stipends were certainly attractive, as many CSUN students work and receive financial aid, but they didn't always understand the career benefits of a $\mathrm{PhD}$, and many struggled with the more immediate goal of graduating from CSUN.

So PUMP changed its strategy to emphasize how it would help students do better in their classes and reach

\section{"It's cool to be in PUMP."}

At the summer institute, participants also learn about doctoral programs in mathematics through presentations by faculty from nearby universities, who explain what they look for in graduate school applicants. In addition, PUMP alumni who are succeeding in graduate school give talks, and what they have to say really hits home. Horn said that many of the more recent PUMP students have told them that this part of the program changed their lives. "The current students now see someone who has a demographic background similar to their own and is doing something they never dreamed of," Horn said. "That gives them the idea, 'I can do that as well.' "

Another component of the PUMP structure is its undergraduate research projects. These take place during the academic year, with PUMP providing a bit of financial support to the faculty and students involved. Djellouli, a co-PI on the original PUMP grant and now chair of the CSUN mathematics department, has worked extensively with students on research projects. He said the projects have become an integral part of the department. "We are now in a situation where it is unusual that an undergraduate student in the department does not do any type of research activity," he said. "Faculty have seen that it works, it helps students, it motivates them and lifts their aspirations." The enthusiasm is now spreading in the CSU Alliance departments, where faculty can apply to PUMP for small grants to support Undergraduate Research Groups (URGs) consisting of a faculty member and at least two students.

The PUMP research projects have a ripple effect in that even after support for the projects ends, the faculty and students often continue to work together. The activity fosters closer engagement between faculty and students, thereby leading naturally to better mentoring. In addition, students gain experience in presenting their work in the PUMP Symposium, which brings together all the PUMP URG students across the CSU Alliance campuses.

Another component of PUMP is its systematic efforts to get students to apply for off-campus opportunities, such as the many Research Experiences for Undergraduates programs that take place in various locations across the United States. PUMP provides support for students to attend regional and national conferences, such as meetings of chapters of the Mathematical Association of America and the Joint Mathematics Meetings. Many PUMP students attend the Field of Dreams Conference, sponsored by the National Alliance for Doctoral Studies in the Mathematical Sciences. Held annually, Field of Dreams has become one of the major annual events where faculty come together with students from groups underrepresented in the mathematical sciences. 


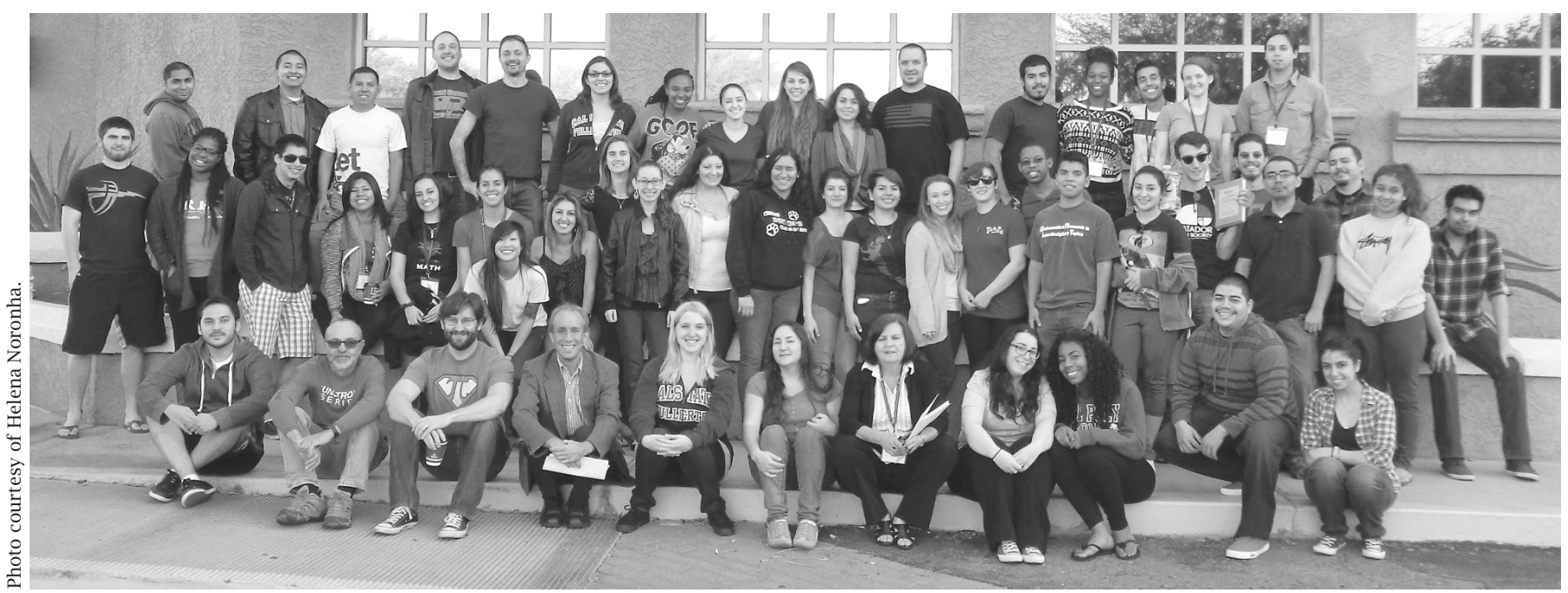

PUMP students attend the 2014 Field of Dreams conference.

\section{Positive Effects on the Department}

The CSUN mathematics department soon saw the positive effects of PUMP. Faculty reported that they could teach at a deeper level than before. More undergraduate students were turning up in the department's master's-level courses. The department was able to augment its degree offerings to include a bachelor of science option, which specifically prepares majors for graduate school. Prior to PUMP, most math majors took the department's secondary teaching option for their degrees. Today there are over 110 majors in the BS/BA option versus around fifty in the secondary teaching option; around 35 students are in the applied mathematics/statistics option.

Students are also finding the department a more welcoming place. CSUN is largely a commuter campus, and prior to PUMP many mathematics students would come for two hours to attend a class and then leave to work jobs or take care of their families. "They did not stick around on campus," Horn remarked. But with

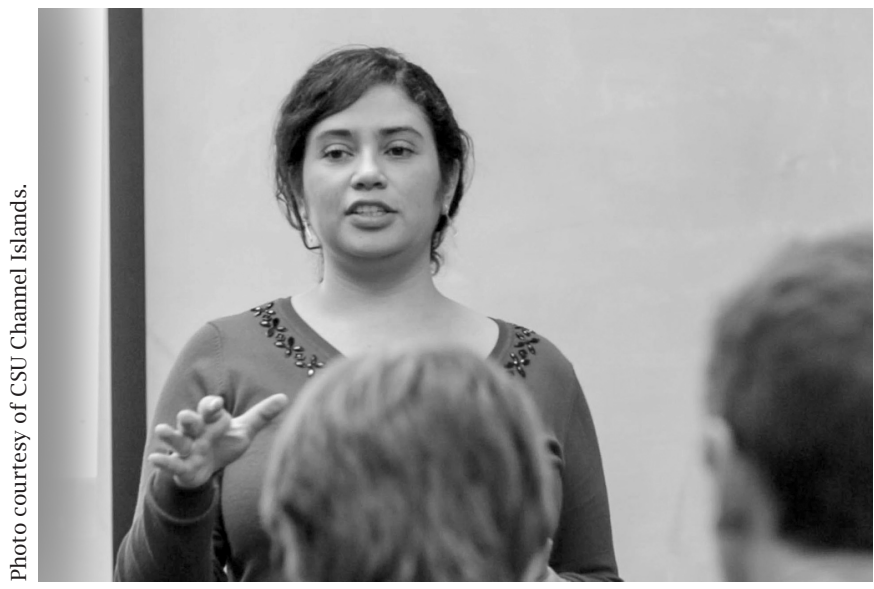

Cynthia Flores lectures to her students at Cal State University Channel Islands.
PUMP, more students are staying on campus for a full day. The department has helped in various ways, such as providing tutoring jobs for advanced undergraduates and designating a room where students can hang out and work together. Now, said Horn, "There is an undergraduate and beginning graduate mathematical community" within the department. "And it all started with the original PUMP grant from 2005."

An increasing number of CSUN math majors are entering and progressing in doctoral programs. Between 2005 and 2015, over 50 CSUN math majors entered PhD programs. They are well equipped for the rigors of graduate school; very few have dropped out. Moreover, Horn said that in the few cases where students have dropped out, the reasons were always personal. "I know of no case where it was for academic reasons," he noted. Prior to PUMP, the number of CSUN math majors going to graduate school was far smaller. For example, NSF statistics show that between 1996 and 2000, only one CSUN math major completed a PhD. Each year between 2007 and 2012, an average of five CSUN math majors completed a $\mathrm{PhD}$.

PUMP students have been accepted into some of the top graduate programs in mathematics in the nation and are continuing on to good positions as postdoctoral or junior faculty or in industry. Three PUMP students received NSF Graduate Fellowships. One is CSUN student Evan Randles, who went to Cornell. The other two are from Cal Poly Pomona and participated in the CSU-Alliance for PUMP: Kristin Dettmers, in applied mathematics at MIT, and Natalie Gasca, in statistics at the University of Washington. Another PUMP student, William Yessen, received an NSF Postdoctoral Fellowship and is at Rice University. Such distinctions for Cal State students were extremely rare prior to PUMP.

\section{Student Successes}

There are many inspiring stories among the PUMP students, and one is that of Cynthia Flores. To say that she 
was the first in her family to attend college seems inadequate to describe the enormous leap she has made. Her parents fled El Salvador as civil war raged, got amnesty in the United States, and settled in Los Angeles. Although she grew up a few blocks from the University of Southern California, she had no idea what it was, and no one around her did either. She suspected it was a church, "since everyone who went there dressed nice," she said. When she was identified as gifted at the age of six, she and her parents were not sure what the term meant, other than that she was given extra assignments. She loved math and excelled in the subject, but by high school she found her math classes dull. On the advice of a guidance counselor, she enrolled in college algebra at a nearby community college and enjoyed it greatly. This was her first inkling of what college would be like.

Intending to become a high school math teacher, Flores enrolled in CSUN. She did well academically but held many misconceptions about career paths. She thought that college professors were people who had been outstanding high school teachers and had been promoted. It was not until Flores enrolled in PUMP that Noronha explained the actual career path of a mathematics professor. Given Flores's excellent grades, Noronha recommended she stay on for a master's degree at CSUN and then apply to graduate school. PUMP "changed my life," Flores said. A major factor was the dedication of the PUMP faculty. "They strike a balance between mentoring, advising, and rigorous teaching" that provided a strong foundation for graduate school, she said.

Today, as assistant professor at California State University Channel Islands, Flores is once again involved with PUMP, through the CSU Alliance. Like the other universities in the alliance, Channel Islands is a Hispanic-serving institution. PUMP allows the mathematics faculty there to capitalize on their experience mentoring students from underrepresented groups. Said Flores, "I am so excited that PUMP is making a difference in the lives of many underserved undergraduate students."

Another PUMP student, Sam Fleischer, has a very

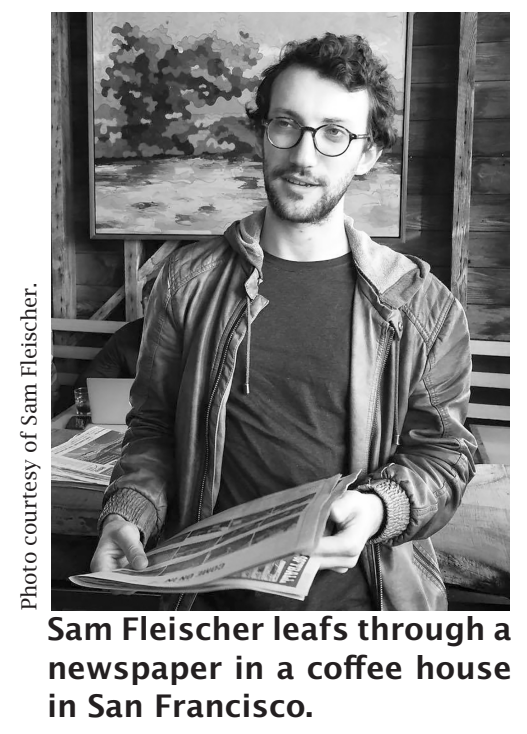

different story. Out of high school he was accepted into a toplevel art conservatory in New York. He studied theater there for a year and a half before deciding that wasn't what he wanted to do. He ended up at CSUN mainly because his mother works there and he got a tuition reduction. After entering PUMP, he attended a Field of Dreams conference and began exploring predator-prey models under the guidance of CSUN math professor Jing Li. "Clearly, PUMP has had a direct, positive effect on my career as a mathematician," he said.

Fleischer is now a doctoral student and teaching assistant at UC Davis. He noted that if his original goal had been an academic career, he might have tried for one of the many fancier institutions in the Los Angeles area. But after taking part in PUMP at CSUN, he has no regrets. "I ended up having a great experience, since there was less competition to do research with professors and I received lots of one-on-one attention when I sought it out in office hours," he said. His experience at UC Davis made him appreciate CSUN and PUMP all the more. For undergraduates at big research-oriented universities, he observed, "there is much greater potential to get lost and not receive adequate attention from professors."

\section{Keys to Success}

One reason PUMP is so successful in getting underrepresented minority students into mathematics is that PUMP lives where these students live. While other programs make heroic efforts to recruit qualified students from underrepresented groups, CSUN does essentially no recruiting for PUMP. The same is true for the institutions in the CSU Alliance for PUMP, where the percentage of Hispanic students ranges between 25 and 50 percent.

Programs that recruit underrepresented students often must put in a lot of effort to strengthen the students' backgrounds to prepare them for graduate school. PUMP works differently in that its summer program reaches students much earlier, when they are sophomores or juniors. As Djellouli put it, PUMP operates at a "crossroads" point for the students. By the time PUMP students are seniors, "they know so many things about mathematics, about the beauty of math, the variety of the math, and also about possible jobs, whether in academia or industry," he said. "Also, they know themselves.... Those who decide to go into PhD programs really know that this is what they want. These are not students who are going to start and drop."

The success of PUMP has put CSUN on the map in various ways. Students at community colleges in California who are interested in mathematics often want to transfer to CSUN for bachelor's degrees, to join PUMP. The department is able to attract very good job candidates who fit its elevated profile as a center for undergraduate research. For the first time, the department is getting job applications from overseas candidates. Also for the first time, CSUN's very own alumni are applying for jobs in the department.

The effects of PUMP have also raised the profile of the mathematics department on the CSUN campus. As the largest department in terms of enrollments, mathematics used to be viewed solely as a service teaching department. That view has shifted, as the department has become more research-oriented, partly because of PUMP and partly because of new hires. Also, the number of students the mathematics department sends to graduate programs is now on a par with, for example, the biology department. 
"We are a little more respected now as a valid academic department," said Horn.

What PUMP has done at CSUN and is now spreading to the other campuses in the CSU Alliance is to foster a "doctoral culture" in an undergraduate institution. PUMP students thrive in this culture. And in the end, the students are the real reason for the success of PUMP. PUMP provides a structure and setting where the students' knowledge and aspirations can blossom. Said Djellouli, "The students when we talk to them, they are so happy, so thankful that they had this opportunity."

\section{CSU Alliance for PUMP}

The CSU Alliance for PUMP comprises the following campuses in the California State University system:

$\begin{array}{ll}\text { Channel Islands } & \text { Los Angeles } \\ \text { Dominguez Hills } & \text { Northridge } \\ \text { Fresno } & \text { Pomona } \\ \text { Fullerton } & \text { San Marcos } \\ \text { Long Beach } & \text { San Bernardino }\end{array}$




\section{In Her Own Words: A PUMP Success Story}

PUMP had a very strong impact on my academic goals and achievements, so I am very passionate about this program.

I was accepted into the PUMP Summer Program in 2011, during my sophomore year. Until then I was set on becoming a math teacher, mainly because teaching was familiar, since my mom is a teacher. But I wanted to learn more about graduate school because academics is what I really enjoyed and excelled in.

A week before PUMP started, I found out I was expecting my first child-I was only nineteen years old. I had always hoped to become a mother, but at such a young age and in an unplanned situation, I felt as if I had failed. I felt I was no longer a good role model for my family. I am from the Northridge area and am the oldest of my cousins and siblings. We grew up in a low-income area with not so many great influences, so I had a lot of pressure to be "perfect". How could I consider graduate school when I was unsure I would even be able to finish my undergraduate degree?

I decided to attend PUMP anyway, and I am glad I did. Many PUMP guest speakers told of their experiences. One of them was earning her $\mathrm{PhD}$ and had her first child at age eighteen. Meeting her gave me hope. After the program I really considered making a PhD my goal and sought more opportunities that could help me get there. However, while trying to talk about my goals with professors, some of them put me down. One reacted with rolling eyes when I said I'd be taking a semester off because I was pregnant. Another lectured me about how long it took some women to earn their PhDs. Another just sighed. I was filled with guilt, anger, sadness. But I wanted to prove them wrong. I had to keep reminding myself of the women I had met in PUMP.

I had my son in January 2013. Although I took some time off classes, I found another opportunity to go after: The PUMP Undergraduate Research Group (URG). That was a perfect fit for me because it allowed me to gain research experience and did not require me to move out of state.

The URG helped me realize that I really enjoy computational biology, analyzing data, and building mathematical models. This experience led me to consider graduate programs in computational biology and biostatistics. My URG research advisor Bruce Shapiro was very supportive of my career path and my new status as a mother. He offered me an opportunity to continue the research at Caltech, where I collaborated with biologists, presented my work at a large conference, and learned new programming skills.

After that, I was accepted to do the PUMP Summer Program and PUMP URG a second time. I was mentored by Ramin Vakilian in multiple research projects and attended more conferences to present our work. Both he and PUMP founder Helena Noronha supported me and wanted to see me succeed.

During my last year, I applied to graduate programs, mostly teaching credential and master of education programs. I wanted to retreat to something that was more familiar and that I could do closer to home. Also, the negative responses I'd had from some of the professors during my pregnancy made me wary. However, Helena really pushed me to apply to master's programs in biostatistics, including the one at Duke University.

All but one of the programs I applied to accepted me with scholarships. My mind was set on UCLA, because it was nearest to home and it was a teaching program. But I also went to visit Duke. I did not feel there that negativity I had encountered before---people actually wanted to know more about my son and my experience. I kept reminding myself of what I had learned at PUMP and how many of the people I met there had struggles but overcame them and were succeeding. During the last week before decision deadlines, my scholarship from Duke was increased.

I am now in the master of biostatistics program at Duke University. I owe so much of where I'm at today to PUMP. It paved the way for many opportunities and gave me confidence to keep pushing through. It has definitely been challenging, but I'm making it just fine. As for my son, he is now three and is loving the new sights in North Carolina.

-Brianna Amador 


\section{A View from a CSU Alliance Member}

I first heard about PUMP when I met Helena Noronha at a conference at Harvey Mudd College in 2013. I could hardly believe that such a program exists: stipends for Cal State faculty and students to learn mathematics and conduct research together. I got involved in the CSU Alliance for PUMP and ran the 2014 PUMP Summer Program at my university, Cal Poly Pomona. I also applied for and received support to conduct research with a pair of undergrads (one of whom, Kristin Dettmers, is now at MIT pursuing her PhD in applied math).

What makes PUMP so successful is the confidence it ignites in its students. PUMP applicants are typically underrepresented students who may not have ever thought about pursuing a graduate degree in math. The PUMP Summer Program provides a unique opportunity at a critical point in their development to learn about proofbased mathematics beyond

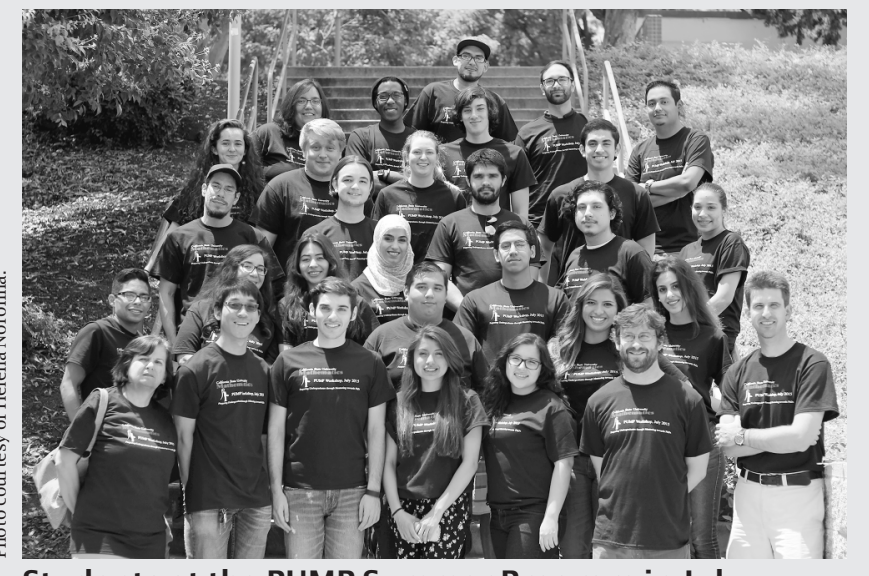

Students at the PUMP Summer Program in July 2015. In the front row are PUMP director Helena Noronha on the far left and, on the far right, two Cal Poly Pomona faculty members who are co-directors of the CSU Alliance for PUMP, John Rock and Arlo Caine. and service responsibilities. The stipends faculty receive through the PUMP Undergraduate Research Groups (URG) are crucial.

Similarly, the stipends provided to the students allow them to forgo part-time work and focus on their mathematical development. Plus, PUMP supports the computations of calculus courses in a challenging and supportive environment. The stipend and lodging support the Summer Program provides are vital: without this monetary support, many applicants might, for example, be under pressure to make money by taking a part-time job to support themselves or their families.

CSU Alliance member departments see improvement in the performance of students who have taken part in the PUMP Summer Program and an increase in the number of math faculty who conduct research with undergraduates. Cal State faculty members are always encouraged to conduct research with students, but this is frequently not feasible due to our significant teaching program to grow beyond ing mathematics programs across the country.

\section{-John Rock, Cal Poly Pomona, co-director, CSU Alliance for PUMP}

